\title{
Substituição de milho por sorgo triturado ou extrusado em dietas para eqüinos 1
}

\section{Alexandre Augusto de Oliveira Gobesso ${ }^{2}$, Eliana D'Auria ${ }^{3}$, Lígia Dias Prezotto4, Francisco Palma Rennó ${ }^{2}$}

\author{
1 Projeto financiado pela FAPESP - Fundação de Amparo à Pesquisa do Estado de São Paulo. \\ 2 Departamento de Nutrição e Produção Animal, Faculdade de Medicina Veterinária e Zootecnia, Universidade de São Paulo, Caixa Postal \\ 23, CEP: 13630-970, Pirassununga, SP. \\ ${ }^{3}$ FAFRAM, Ituverava/SP. \\ ${ }^{4}$ Zootecnista, FZEA/USP. Bolsista Iniciação Científica CNPq.
}

RESUMO - Avaliou-se a substituição de milho triturado ou extrusado por sorgo triturado ou extrusado no concentrado utilizado em dietas para eqüinos. Utilizaram-se quatro éguas com peso médio de $450 \mathrm{~kg}$ e 24 meses de idade, sem raça definida, em um delineamento experimental quadrado latino $4 \times 4$, em esquema fatorial. Avaliaram-se a digestibilidade aparente total da dieta e dos nutrientes e o perfil metabólico dos animais considerando os valores plasmáticos de glicose e insulina pós-ingestão das dietas. As dietas contendo milho e sorgo extrusado proporcionaram coeficientes de digestibilidade total da matéria seca (MS), matéria orgânica (MO), proteína bruta (PB), fibra em detergente neutro (FDN) e fibra em detergente ácido (FDA) maiores que os obtidos com dietas contendo estes ingredientes triturados. Os coeficientes de digestibilidade aparente total do amido foram semelhantes entre as dietas. A resposta glicêmica e insulinêmica foi maior quando fornecidas as dietas extrusadas, logo, o processamento provocou alterações no metabolismo dos eqüinos. A total substituição do milho pelo sorgo em dietas para eqüinos é possível, uma vez que os coeficientes de digestibilidade dos nutrientes e os níveis plasmáticos de glicose e insulina não diferiram entre as formas de processamento do sorgo testadas. A forma de processamento do milho e do sorgo por extrusão aumenta os coeficientes de digestibilidade do amido e melhora o potencial energético da dieta.

Palavras-chave: digestibilidade aparente, glicemia, insulinemia, processamento de grãos

\section{Replacement of corn by ground or extruded sorghum in diets for horses}

ABSTRACT - The aim of this work was to evaluate, the replacement of ground or extruded corn by sorghum ground or extruded in the concentrate used in diets for equines. Four mares with an average weight of $450 \mathrm{~kg}$ and 24 months of age, nondefined breed were distributed to a $4 \times 4$ Latin square experimental design in a $2 \times 2$ factorial arrangement (ingredient - corn and sorghum $\times$ processing form - ground and extruded). Apparent digestibility of total diet and nutrients were evaluated, and also the metabolic profile of the animals, considering the values of plasma glucose and insulin after ingestion of diets. Diets with extruded corn and sorghum provided higher total apparent digestibility of dry matter, organic matter, crude protein, neutral detergent fiber and acid detergent fiber higher than those obtained with diets containing these ground ingredients. Total apparent digestibility of starch was similar among diets. Glycemic and insulinemic response was higher when fed extruded diets hence grain processing forms caused changes in the metabolism of horses. Total replacement of corn by sorghum in diets for horses is possible, since the apparent digestibility of nutrients and plasma levels of glucose and insulin did not differ between processing forms of sorghum. Regarding to processing forms, extruded corn and sorghum showed highest starch apparent digestibility and improved the energy potential of the diet.

Key Words: apparent digestibility, blood glucose, insulin, grain processing

\section{Introdução}

Ensaios de digestibilidade utilizando-se o método de coleta total de fezes em eqüinos auxiliam na avaliação da digestibilidade aparente total, ou seja, possibilitam informações para o entendimento da digestão dos nutrientes no trato gastrintestinal. A digestão dos eqüinos pode ser dividida em duas fases: a pré-cecal, cuja ação predominante é a enzimática, e a pós-ileal, cuja ação é microbiana (Meyer, 1995). Essas diferenças, conseqüentemente, podem influenciar na forma como os nutrientes são absorvidos e, inclusive, podem interferir diretamente na perda de energia digestível (Radicke et al., 1991).

Outro parâmetro utilizado para avaliar dietas para eqüinos é a concentração plasmática de glicose e insulina. Estudos têm indicado que a análise da composição em 
carboidratos dos alimentos fornecidos para eqüinos pode não ser a melhor forma de prever a resposta glicêmica, portanto, a relação entre a glicose e a insulina plasmática imediatamente após a alimentação pode ser extremamente importante nesta avaliação (Stull \& Rodiek, 1988). Entretanto, há pouca informação disponível, o que indica a influência das fontes de amido ou das técnicas de processamento dos grãos nos níveis glicêmicos de eqüinos (Vervuert et al., 2004).

Como fonte de concentrado energético, o milho é o cereal mais utilizado na formulação de dietas para animais. No entanto, este cereal é também utilizado na alimentação humana, uma concorrência que desfavorece sua utilização em rações. Assim, pesquisas têm sido realizadas objetivando a substituição do milho em rações para animais outros alimentos concentrados energéticos. Entre os alimentos avaliados, destaca-se o sorgo, que possui composição química semelhante à do milho (Saint Just, 1989), embora com valor energético ligeiramente inferior e um pouco mais rico em teor protéico. O menor valor nutritivo do sorgo em comparação ao milho está relacionado à menor digestibilidade causada pela interferência dos taninos no metabolismo de proteínas e carboidratos, especialmente em grãos de sorgo com mais de $1 \%$ de taninos (Fialho \& Rutz, 1985).

A finalidade do processamento de alimentos é aumentar a disponibilidade de nutrientes para os animais e preservar a qualidade desses nutrientes na matériaprima por maior tempo.

De acordo com Lewis (2000), os grãos podem ser processados frios ou quentes. O processamento frio é geralmente uma moedura em martelo hidráulico ou em moinho de roda. O processamento quente é feito por floculação, expansão, micronização, extrusão ou peletização. O nível de floculação e gelatinização do amido é determinado pelo tempo de exposição ao vapor e à temperatura, à umidade do grão, ao tamanho e à distância entre os rolos e ao tipo de grão (Menezes Jr., 1999; Owens et al., 1997).

Nos grãos sem tratamento ou tratados mecanicamente, o grau de gelatinização (porcentagem do conteúdo total de amido imediatamente acessível à glicoamilase) é normalmente zero, entretanto, nos cereais processados por calor, espera-se que o amido seja gelatinizado (Vervuert et al., 2004). Conseqüentemente, a disponibilidade dos grânulos de amido para enzimas digestivas é aumentada pelo grau de gelatinização (Holm et al., 1988; Selmi et al., 2000).

Neste trabalho, avaliou-se a substituição do milho por sorgo triturado ou extrusado no concentrado utilizado em dietas para eqüinos.

\section{Material e Métodos}

O experimento foi realizado nas dependências do Setor de Eqüideocultura do Campus Administrativo de Pirassununga, utilizando-se quatro éguas com média de 24 meses de idade e peso médio de $450 \mathrm{~kg}$, pertencentes ao rebanho da Universidade de São Paulo.

Utilizou-se um delineamento experimental em quadrado latino $4 \times 4$, com quatro animais, quatro tratamentos e quatro períodos, em esquema de arranjo fatorial.

As dietas foram formuladas para atender as exigências de mantença de éguas em idade adulta, não-gestantes, segundo o Nutrient Research Council (NRC, 1989), e foram compostas de feno e concentrado (tratamento) à base de milho ou sorgo triturados ou extrusados (Tabela 1). Os concentrados foram compostos de farelo de soja $(8,0 \%)$, farelo de trigo $(27,8 \%)$, milho ou sorgo $(48,5 \%)$, feno de gramínea $(10,0 \%)$, calcita $(2,8 \%)$, núcleo $(1,9 \%)$ e sal $(1,0 \%)$.

$\mathrm{O}$ experimento foi dividido em quatro períodos de 11 dias (os oito primeiros de adaptação às dietas experimentais e os três dias subseqüentes para coleta de amostras). Os animais foram mantidos em baias individuais de alvenaria $\left(12 \mathrm{~m}^{2}\right)$ sem cama nos três dias de coleta total de fezes.

A dieta foi fornecida duas vezes ao dia, em intervalos constantes, às 7 e $19 \mathrm{~h}$, divididas em partes iguais, considerando consumo diário individual de $2,0 \%$ do peso vivo/ $\mathrm{kgMS} / \mathrm{dia}$, com $50 \%$ de concentrado e $50 \%$ de volumoso (feno da gramínea Coastcross, Cynodon dactilon, L. Pers). O concentrado foi fornecido simultaneamente ao volumoso, em cochos separados, observando-se o tempo máximo de consumo do concentrado de 45 minutos com o objetivo de padronizar os estudos de digestibilidade, segundo metodologia adotada por Gibbs \& Schelling (1996). O fornecimento de água e suplemento mineral foi à vontade. Os animais foram pesados no início e ao final de cada período experimental.

Amostras individuais das dietas fornecidas foram obtidas diariamente durante os períodos de coleta e acondicionadas em sacos plásticos para posteriores análises bromatológicas. As fezes foram coletadas (durante 24 horas dos três dias de coleta), pesadas, homogeneizadas, amostradas (10\%), devidamente identificadas e armazenadas em freezer horizontal a $-18^{\circ} \mathrm{C}$ para posterior análise.

A digestibilidade total de amido, matéria seca, matéria orgânica, proteína bruta, fibra em detergente neutro e fibra em detergente ácido foi avaliada segundo metodologia descrita por Silva (2002) utilizando-se quatro dietas, cujas fontes de variação foram a fonte de amido e a forma de processamento. 
Tabela 1 - Composição do feno e dos concentrados (\%MS)

\begin{tabular}{|c|c|c|c|c|c|}
\hline & \multirow[t]{3}{*}{ Feno de Cynodon dactilon } & \multicolumn{4}{|c|}{ Concentrado } \\
\hline & & \multicolumn{2}{|c|}{ Milho } & \multicolumn{2}{|c|}{ Sorgo } \\
\hline & & Triturado & Extrusado & Triturado & Extrusado \\
\hline Matéria seca & 88,45 & 89,07 & 90,18 & 88,77 & 90,45 \\
\hline Matéria orgânica & 83,84 & 81,80 & 84,36 & 82,71 & 83,67 \\
\hline Matéria mineral & 4,61 & 7,27 & 5,82 & 6,06 & 6,78 \\
\hline Extrato etéreo & 1,10 & 2,86 & 1,86 & 2,30 & 1,71 \\
\hline Fibra bruta & 33,89 & 6,13 & 6,91 & 8,05 & 6,87 \\
\hline Proteína bruta & 5,38 & 13,70 & 13,60 & 13,86 & 14,17 \\
\hline Cálcio & 0,32 & 1,89 & 1,72 & 1,33 & 1,53 \\
\hline Fósforo & 0,20 & 0,53 & 0,54 & 0,53 & 0,55 \\
\hline Fibra em detergente ácido & 42,25 & 11,31 & 12,56 & 13,36 & 13,84 \\
\hline Fibra em detergente neutro & 85,13 & 24,80 & 27,34 & 29,06 & 28,62 \\
\hline Amido & 2,55 & 46,93 & 48,07 & 47,36 & 47,90 \\
\hline
\end{tabular}

No primeiro dia de coleta de fezes, também foram realizadas as coletas de sangue, por punção da veia jugular, às 6h30 (30 minutos antes do fornecimento do concentrado), às $7 \mathrm{~h} 30,8 \mathrm{~h} 30,9 \mathrm{~h} 30,10 \mathrm{~h} 30,11 \mathrm{~h} 30$ e $12 \mathrm{~h} 30$ (após a alimentação) e, ainda, às $7 \mathrm{~h}$ para dosagem de glicose e insulina, segundo metodologia descrita por Stull \& Rodiek (1988).

Os coeficientes de digestibilidade e os níveis plasmáticos de glicose e insulina foram analisados pelo programa computacional Statistical Analysis System (SAS, 1985), verificando-se anteriormente a normalidade dos resíduos pelo teste de Shapiro-Wilk (Proc Univariate) e a homogeneidade das variâncias pelo teste F. A análise de variância foi realizada pelo procedimento GLM General Linear Model e PROC EXP e as médias comparadas pelo teste de Tukey a $5 \%$ de probabilidade.

Durante a fase de coleta de amostras, o peso dos eqüinos foi avaliado no início e final de cada período e não apresentou variação significativa, o que indica que a dieta foi adequada à categoria animal em estudo.

\section{Resultados e Discussão}

Os coeficientes de digestibilidade total de matéria seca, matéria orgânica, proteína bruta, fibra em detergente neutro e fibra em detergente ácido foram maiores $(\mathrm{P}<0,05)$ quando fornecidas as dietas com grãos extrusados (Tabela 2).

A digestibilidade de FDN e FDA melhorou quando fornecidas as dietas contendo milho ou sorgo extrusado. A melhor digestibilidade da fibra e da proteína da dieta contendo sorgo extrusado resultou em maior digestibilidade da matéria orgânica desta mesma dieta em comparação àquela com sorgo triturado, o que indica efeito do processamento por extrusão.
Os resultados observados neste experimento refletiram as condições de cada concentrado testado e, em alguns casos, observaram-se resultados semelhantes aos obtidos por Meyer et al. (1995), que concluíram que podem ocorrer variações individuais na digestibilidade de um mesmo alimento, causadas pelo comportamento durante a ingestão do alimento (tempo de mastigação), pela alteração de peristaltismo, por diferenças na produção de enzimas ou por parasitoses. Manzano (1978), citando Olsson \& Ruudvere (1955), relataram que a digestibilidade pode ser influenciada pela composição química e quantidade de alimentos ingeridos, pela velocidade de trabalho, pelo grau de moagem e teor de umidade dos alimentos, pela quantidade de fibra e pelo tempo de passagem dos alimentos pelo trato digestivo.

O coeficiente de digestibilidade aparente total do amido neste estudo foi semelhante entre as dietas. Essa semelhança foi observada também por Kienzle (1994), em experimento no qual a digestibilidade aparente total de amido de diversas dietas variou muito pouco, em virtude da alta digestão microbiana desse nutriente.

Segundo Whitaker \& Carvalho (1997), a utilização do sorgo granífero como fonte alternativa de energia na alimentação animal tem resultados difíceis de ser comparados, em virtude da variabilidade na composição química das variedades e da diversidade de métodos para análise do teor de tanino. No entanto, esses autores sugeriram que o uso do sorgo com alto teor de tanino deve ser limitado, principalmente para animais não-ruminantes, a não ser que os grãos sejam processados por métodos físicos ou químicos de detoxificação. Por outro lado, seu valor nutritivo do sorgo de baixo tanino é semelhante ao do milho, logo, esse alimento pode ser utilizado em substituição a até $30 \%$ do milho em rações para eqüinos em crescimento. 
Tabela 2 - Digestibilidade total (\%) de nutrientes das dietas experimentais

\begin{tabular}{|c|c|c|c|c|c|}
\hline & \multicolumn{4}{|c|}{ Concentrado } & \multirow[t]{3}{*}{$\mathrm{CV}$} \\
\hline & \multicolumn{2}{|c|}{ Milho } & \multicolumn{2}{|c|}{ Sorgo } & \\
\hline & Triturado & Extrusado & Triturado & Extrusado & \\
\hline Matéria seca & $61,98 b$ & $64,78 \mathrm{a}$ & $62,45 b$ & $64,43 \mathrm{a}$ & 4,23 \\
\hline Matéria orgânica & $63,17 b$ & $66,28 \mathrm{a}$ & $62,22 b$ & $65,79 a$ & 4,91 \\
\hline Proteína bruta & $64,77 b$ & $68,83 \mathrm{a}$ & $65,32 b$ & $67,76 \mathrm{a}$ & 4,03 \\
\hline Amido & $99,53 \mathrm{a}$ & $99,54 \mathrm{a}$ & $99,39 a$ & $99,61 \mathrm{a}$ & 0,15 \\
\hline Fibra em detergente ácido & $46,97 b$ & $51,71 \mathrm{a}$ & $48,44 b$ & $51,89 a$ & 8,40 \\
\hline Fibra em detergente neutro & $54,19 b$ & $58,12 \mathrm{a}$ & $56,45 b$ & $58,46 a$ & 5,70 \\
\hline
\end{tabular}

a,b Médias seguidas por letras distintas diferem $(P>0,05)$ pelo teste Tukey.

Lewis (2000) concluiu que o aquecimento e a moagem suficientes para desintegrar o grão de milho e sua estrutura granular amilácea aumentam a quantidade de amido digerido no intestino delgado dos eqüinos. Potter et al. (1992) afirmaram que o processamento tem pequeno efeito sobre a digestibilidade em todo o trato gastrointestinal dos eqüinos, mas pode afetar o local de digestão de determinados nutrientes.

Nesta pesquisa, observou-se aumento na concentração de glicose plasmática $(\mathrm{P}<0,05)$ após a ingestão das dietas e, diferentemente do observado por Gobesso (2001), houve diferença nos valores de glicose plasmática (Figura 1) entre as dietas e os horários de coleta $(\mathrm{P}<0,05)$. As dietas contendo sorgo extrusado apresentaram, na média, valores superiores aos das dietas contendo sorgo triturado, estatisticamente.

No tempo de 30 minutos antes da ingestão do concentrado, não houve diferença entre as dietas. A partir dos 30 minutos e até 210 minutos após a ingestão, houve um nível mais alto de glicose plasmática nas dietas com sorgo extrusado. Aos 270 minutos, não houve diferença e aos 330 minutos, as dietas à base de milho apresentaram valores maiores que os obtidos com aquelas com sorgo.

A curva da glicose plasmática obtida com as dietas com grãos extrusados apresentou picos mais elevados, uma vez que o processamento por extrusão disponibiliza mais amido para digestão, em virtude da quebra das ligações alfa 1-6 (gelatinização). Quando fornecida a dieta à base de milho extrusado, houve redução tão acentuada na curva de glicose quanto a observada com a dieta à base de milho triturado ( 1 hora de atraso), porém, no tempo 270 minutos, a curva voltou a subir, logo, alguma quantidade de amido ainda estava disponível para o processo de digestão no intestino delgado.

$\mathrm{O}$ amido digerido é absorvido em forma de glicose e alcança a corrente sanguínea, de onde é levado rapidamente para os tecidos pela insulina. Diferentemente do

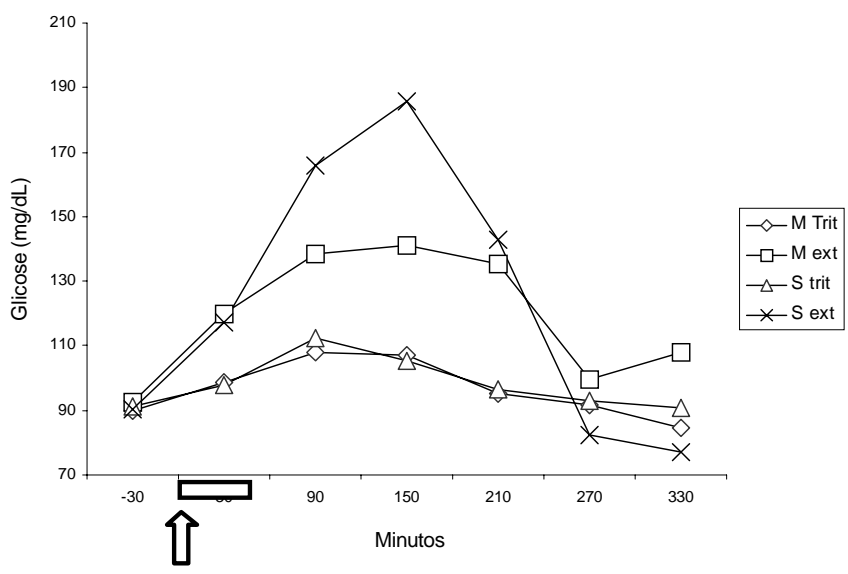

Momento do fornecimento da dieta

$\square$ Tempo de ingestão da fração concentrado da dieta

Figura 1 - Glicose plasmática $(\mathrm{mg} / \mathrm{dL})$ medida antes e após a alimentação no período matutino em eqüinos alimentados com dietas contendo milho ou sorgo triturados ou extrusados.

observado nas dietas com sorgo extrusado, a insulina das dietas com sorgo triturado ocasionou hipoglicemia, mas não provocou redução brusca por volta dos 150 minutos, pois provavelmente o aporte de glicose foi constante e, como a insulina tem meia-vida relativamente curta, a quantidade de glicose retirada é reposta e os níveis de glicose não diminuem, apesar de a glicose ser absorvida constantemente. Em 150 minutos após a ingestão, ainda há certa quantidade de glicose na circulação e, neste momento, a curva é decrescente, pois a partir deste ponto a glicose provavelmente está se esgotando.

A concentração plasmática de glicose após a ingestão de alimento, chamada resposta glicêmica, pode ser influenciada por fatores como tamanho da partícula, grau de processamento térmico, composição em proteína, gordura e fibra do alimento, estrutura bioquímica e processo de 
absorção do carboidrato, conteúdo e intervalo de tempo da refeição anterior (Ralston \& Baile, 1982).

Vervuert et al. (2004) observaram que, 30 a 45 minutos após a alimentação, ocorre significativo aumento nos níveis plasmáticos de glicose e que esses níveis diminuíram para valores basais 150 a 240 minutos após a alimentação. Segundo Healy et al. (1995), eqüinos alimentados com concentrado farelado apresentaram pico de glicose plasmática aos 150 minutos após a ingestão, enquanto naqueles alimentados com concentrado peletizado esse pico ocorreu após 180 minutos, sugerindo que mais glicose foi absorvida da dieta peletizada e comprovando o efeito do processamento.

Testando fontes de amido, Gobesso (2001) avaliou a concentração plasmática de glicose e insulina em eqüinos após a alimentação e observou pico de glicose aos 150 minutos após a ingestão da dieta, enquanto os níveis plasmáticos de insulina aumentaram no primeiro tempo de coleta com pico 150 minutos após a ingestão de três das quatro dietas testadas. Neste estudo, na dieta com sorgo extrusado, o pico ocorreu aos 210 minutos e, na dieta com sorgo triturado, aos 90 minutos.

Considerando a concentração plasmática de glicose da dieta à base de sorgo extrusado, possivelmente houve uma quantidade de amido rapidamente digerida e absorvida na forma de glicose, a qual foi retirada rapidamente da corrente sanguínea pela insulina. As curvas de concentração plasmática de glicose (Figura 1) comprovam que o pico da curva glicêmica para as dietas com milho extrusado, milho triturado e sorgo extrusado ocorreu aos 150 minutos após a ingestão. Esses resultados foram semelhantes aos obtidos por Stull \& Rodiek (1988), que concluíram que a ingestão de carboidratos proporciona, em cavalos, pico de absorção de glicose e insulina 2,5 a 3 horas após a alimentação. Depew et al. (1994) observaram pico de glicose 60 minutos após a ingestão, próximo ao obtido com a dieta com sorgo triturado, que foi aos 90 minutos.

Foram observadas diferenças $(\mathrm{P}<0,05)$ entre as dietas com grãos extrusados e triturados, o que difere dos resultados obtidos por Vervuert et al. (2004), que alimentaram cavalos com dietas contendo milho triturado, micronizado e aquecido, achatado com calor e expandido e não encontraram diferença nos níveis plasmáticos pós-prandiais de glicose e insulina. Os níveis plasmáticos de insulina aumentaram $(\mathrm{P}<0,05)$ após a ingestão das dietas e, também, entre as dietas $(\mathrm{P}<0,05)$ à base de sorgo extrusado e sorgo triturado. Nos tempos 90 até 270 minutos, os valores foram menores nas dietas à base de sorgo triturado em relação ao sorgo extrusado e, no tempo 330 minutos, foram maiores na

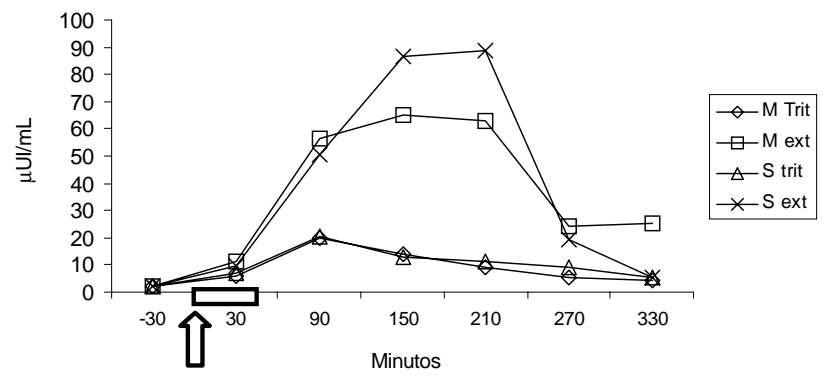

Momento do fornecimento da dieta

Tempo de ingestão da fração concentrado da dieta (45 minutos)

Figura 2 - Níveis plasmáticos de insulina $(\mu \mathrm{UI} / \mathrm{mL})$, antes e após a alimentação da manhã, em eqüinos alimentados com dietas à base de milho ou sorgo triturados ou extrusados.

dieta com milho extrusado. Na avaliação das curvas plasmáticas de glicose e insulina, observou-se que os picos ocorreram aos 150 e 210 minutos para a dieta com sorgo extrusado, aos 90 minutos para a dieta com sorgo triturado e aos 150 e 90 minutos para a dietas com milho triturado. Resultados semelhantes foram observados por Witham \& Stull (1988), que relataram que o pico de glicose plasmática foi obtido 2 a 3 horas após a ingestão de alimento no período da manhã e o de insulina 3 a 4 horas após a alimentação. Segundo esses autores, os níveis de glicose e insulina aumentam imediatamente antes da ingestão, o que não ocorreu neste experimento.

Os valores plasmáticos de glicose e insulina, na média das quatro dietas, independentemente do tempo, foram melhores quando fornecidas as dietas com grãos extrusados, o que também foi observado por Potter et al. (1992), que concluíram que a peletização pode aumentar a digestibilidade do amido no intestino delgado, uma vez que a ingestão de alimentos peletizados aumenta significativamente a concentração plasmática de glicose e insulina em comparação a outros alimentos não processados.

Os valores mais altos da área abaixo da curva da resposta plasmática pós- ingestão, para glicose e insulina, foram observados quando fornecidas as dietas com milho (Tabela 3). Verificaram-se diferenças significativas entre as dietas com grãos extrusados e aquelas com grãos triturados, resultados que divergem dos obtidos por Vervuert et al. (2004), que alimentaram cavalos com dietas contendo milho triturado, micronizado e aquecido, achatado com calor e expandido e não encontraram diferença na AAC de glicose e insulina pós-prandial. 
Tabela 3 - Valores da área abaixo da curva $(A A C)$ da resposta plasmática de glicose $(\mathrm{mg} / \mathrm{dL} \times$ tempo) e insulina $(\mu \mathrm{Ul} / \mathrm{mL} \times$ tempo) e seus respectivos coeficientes de variação

\begin{tabular}{llrr}
\hline Dieta & Glicose & CV $(\%)$ & Insulina \\
\hline Milho triturado & $575,8712 \mathrm{~b}$ & 3,90 & $53,4230 \mathrm{~b}$ \\
Milho extrusado & $717,6163 \mathrm{a}$ & 9,69 & $244,3958 \mathrm{a}$ \\
Sorgo triturado & $602,3258 \mathrm{~b}$ & 8,98 & $62,5876 \mathrm{~b}$ \\
Sorgo extrusado & $762,3818 \mathrm{a}$ & 6,24 & 38,79 \\
Média & 664,5487 & 13,91 & 33,19 \\
\hline
\end{tabular}

a,b Médias seguidas da mesma letra não diferem $(P>0,05)$ pelo teste Tukey.

\section{Conclusões}

Considerando os resultados de digestibilidade aparente total e resposta plasmática de glicose e insulina pósingestão, o milho pode ser substituído totalmente pelo sorgo em dietas para eqüinos. O processamento de extrusão dos grãos de milho e sorgo para utilização em dietas para eqüinos pode melhorar a digestibilidade dos nutrientes e a resposta glicêmica e insulinêmica.

\section{Literatura Citada}

DEPEW, C.L.; THOMPSON JR., D.L.; FERNANDEZ, J.M. et al. Changes in concentration of hormones, metabolites, and aminoacids in plasma of adult horses relative to overnight feed deprivation followed by a pellet-hay meal feet at noon. Journal of Animal Science, v.72, p.1530-1539, 1994.

FIALHO E.T.; RUTZ, F. Utilização de sorgo em rações para suínos. Suinocultura Industrial, v. 83, p.39-43, 1985.

GIBBS, P.G.; SCHELLING, G.T. The significance of small vs. large intestinal digestion of cereal grain and oilseed protein in the equine. Journal of Equine Veterinary Science, v.16, n.2, p.60-65, 1996.

GOBESSO, A.A.O. Digestibilidade total e parcial do amido de diferentes fontes energéticas em eqüinos fistulados no íleo. Jaboticabal: Universidade Estadual Paulista, 2001. 98p. Tese (Doutorado em Zootecnia) - Universidade Estadual Paulista, 2001.

HEALY, H.P.; SICILIANO, P.D.; LAWRENCE, L.M. Effect of concentrate form on blood and gastric fluid variables in ponies. Journal of Equine Nutrition, v.15, n.10, p.423-428, 1995.

HINTZ, H.F. Comparison of digestion coefficient obtained with cattle, sheep, rabbits and horse. Journal of Animal Science, v.28, n.5, p.1045-1066, 1969.

HOLM, J.; LUNDQUIST, I.; BJÕRCK, I. et al. Degree of starch gelatinization, digestion rate of starch in vitro and metabolic response in rats. American Journal of Clinical Nutrition, v.47, p.1010-1016, 1988.

KIENZLE, E. Small intestinal digestion of starch in the horse Revue Médecine Véterinary, v.145, n.3, p.199-204, 1994.

LEWIS, L.D. Nutrição clínica de eqüinos: alimentação e cuidados. São Paulo: Roca, 2000. 710p.

MANZANO, A.; CARVALHO, R.T.L. Digestibilidade aparente de uma ração peletizada e do arraçoamento tradicional em eqüinos, Pesquisa Agropecuária Brasileira, v.13, n.4, p.92-99, 1978.

MEYER, H.; RADICKE, S.; KIENZLE, E. et al. Investigation on preileal digestion of starch from grain, potato and manioc in horses. Journal of Veterinary Medicine Series, v.42, n.6, p.371-381, 1995 .
NATIONAL RESEARCH COUNCIL - NRC. Requeriments of domestic animals. Nutrient requeriments of horses. 5.rev.ed. Washington, D.C.: National Academy of Sciences, 1989. 100p. OWENS, F.N.; SECRIST, D.S.; HILL, W.J. et al. The effect of grain source and grain processing on performance of feedlot cattle: a review. Journal of Animal Science, v.75, n.3, p.868879,1997

POTTER, G.D.; ARNOLD, F.F.; HOUSEHOLDER, D.D. et al. Digestion of starch in the small or large intestine of the equine. Pferdeheilkunde, v.1, p.107-111, 1992.

QUADROS, J.B.S.; FURTADO, C.E.; BARBOSA, E.D. et al. Digestibilidade aparente e desenvolvimento de eqüinos em crescimento submetidos a dietas compostas por diferentes níveis de substituição do feno de tifton 85 pela casca de soja. Revista Brasileira de Zootecnia, v.33, n.3, p.564-574, 2004.

RADICKE, S.; KIENZLE, E.; MEYER, H. Preileal apparent digestibility of oats and corn starch and consequences for cecal metabolism. In: EQUINE NUTRITION AND PHISIOLOGY SYMPOSIUM, 13., 1991, Calgary, Proceedings... Calgary, 1991. p.43.

RALSTON, S.L.; BAILE, C.A. Plasma glucose and insulin concentrations and feeding behavior in ponies. Journal of Animal Science, v.54, n.6, p.1132-1137, 1982.

ROSTAGNO, H.S. Uso do sorgo gramífero na nutrição de aves e suínos. In: SIMPÓSIO BRASILEIRO DE SORGO, 1., 1977, Brasília. Anais... Sete Lagoas: EMBRAPA/CNPMS, 1979. p.49.

SAINT JUST, C.A. Digestibilidade de nutrientes de rações contendo milho e sorgo em éguas gestantes. Piracicaba, Escola Superior de Agricultura Luiz de Queiroz, 1989. 56p. Dissertação (Mestrado em Agronomia) - Escola Superior de Agricultura Luiz de Queiroz, 1989.

STATISTICAL ANALYSIS SYSTEM - SAS. User's guide. Raleigh: SAS Institute, 1985. (CD-ROM).

SELMI, B.; MARION, D.; PERRIER CORNET, J.M. et al. Amyloglycosidase hydrolysis of high pressure and thermally gelatinized and wheat starches. Journal Agricultural and Food Chemistry, v.48, n.7, p.2629-2633, 2000.

SILVA, D.J.; QUEIROZ, A.C. Análise de alimentos: métodos químicos e biológicos. 3.ed. Viçosa, MG: Universidade Federal de Viçosa, 2002. 235p

STULL, C.L.; RODIEK, A.V. Responses of blood glucose, insulin and cortisol concentrations to common equine diets. American Institute of Nutrition, v.1, p.206-213, 1988.

VERVUERT, I.; COENEN, M.; BOTHE, C. Effects of corn processing on the glycaemic and insulinaemic responses in horses. Journal Animal Physiology and Animal Nutrition, v. 88 , p.348-355, 2004

WHITAKER, H.M.A.; CARVALHO, R.L. Substituição do milho pelo sorgo em rações para eqüinos. Revista Brasileira de Zootecnia, v.26, n.1, p.139-143, 1997.

WITHAN, C.L.; STULL, C.L. Metabolic responses of chronically starved horses to reffeding three isoenergetic diets. Journal of America Veterinary Medicine Association, v.212, n.5, p.691-696, 1988 . 